\title{
Anti-angiogenic SPARC peptides inhibit progression of neuroblastoma tumors
}

\author{
Alexandre Chlenski1, Lisa J Guerrero', Radhika Peddinti2, Jared A Spitz', Payton T Leonhardt'1, Qiwei Yang1, \\ Yufeng Tian' ${ }^{1}$ Helen R Salwen'1 and Susan L Cohn*3
}

\begin{abstract}
Background: New, more effective strategies are needed to treat highly aggressive neuroblastoma. Our laboratory has previously shown that full-length Secreted Protein Acidic and Rich in Cysteine (SPARC) and a SPARC peptide corresponding to the follistatin domain of the protein (FS-E) potently block angiogenesis and inhibit the growth of neuroblastoma tumors in preclinical models. Peptide FS-E is structurally complex and difficult to produce, limiting its potential as a therapeutic in the clinic.

Results: In this study, we synthesized two smaller and structurally more simple SPARC peptides, FSEN and FSEC, that respectively correspond to the $\mathrm{N}$-and C-terminal loops of peptide FS-E. We show that both peptides FSEN and FSEC have anti-angiogenic activity in vitro and in vivo, although FSEC is more potent. Peptide FSEC also significantly inhibited the growth of neuroblastoma xenografts. Histologic examination demonstrated characteristic features of tumor angiogenesis with structurally abnormal, tortuous blood vessels in control neuroblastoma xenografts. In contrast, the blood vessels observed in tumors, treated with SPARC peptides, were thin walled and structurally more normal. Using a novel method to quantitatively assess blood vessel abnormality we demonstrated that both SPARC peptides induced changes in blood vessel architecture that are consistent with blood vessel normalization.
\end{abstract}

Conclusion: Our results demonstrate that SPARC peptide FSEC has potent anti-angiogenic and anti-tumorigenic effects in neuroblastoma. Its simple structure and ease of production indicate that it may have clinical utility in the treatment of high-risk neuroblastoma and other types of pediatric and adult cancers, which depend on angiogenesis.

\section{Background}

Neuroblastoma tumors exhibit a broad spectrum of clinical behavior, reflective of their biologic heterogeneity [1]. Although significant progress has been made in the successful treatment of neuroblastoma tumors with favorable biology, more effective therapeutic strategies are still needed for children with high-risk neuroblastoma [2]. A strong correlation between high-risk tumors and angiogenesis has been reported by us and other investigators $[3,4]$, suggesting that blood vessels may be clinically relevant therapeutic targets. In support of this hypothesis, preclinical studies have demonstrated that neuroblastoma tumor growth can be significantly impaired following treatment with anti-angiogenic agents $[5,6]$.

\footnotetext{
* Correspondence: scohn@peds.bsd.uchicago.edu

${ }^{3}$ Department of Pediatrics, University of Chicago, 900 East 57th Street, KCBD Rm. 5100, Chicago, IL 60637, USA

Full list of author information is available at the end of the article
}

The histologic features of neuroblastoma tumors have also been shown to be prognostic, and an abundance of Schwannian stroma is associated with a more benign tumor phenotype and favorable prognosis [7]. Schwann cells are known to secrete factors that induce neuroblastoma differentiation [8,9]. Studies from our laboratory have demonstrated that Schwann cells also influence neuroblastoma tumor growth by secreting inhibitors of angiogenesis [9], the most potent of which is Secreted Protein Acidic and Rich in Cysteine (SPARC) [10]. SPARC belongs to a group of non-structural components of the extracellular matrix (ECM) that modulate interactions between cells and their environment [11,12]. It is highly expressed in a variety of cell types associated with remodeling tissues [13]. Although the mechanism for its anti-angiogenic activity is not well understood, SPARC is capable of interfering with the binding of angiogenic stimulators vascular endothelial growth factor (VEGF), platelet-derived growth factor (PDGF), and basic fibro- 
blast growth factor (bFGF) to their receptors in endothelial cells, resulting in inhibited proliferation [14]. SPARC has also been shown to down-regulate VEGF in glioma cells [15].

The role of SPARC in tumorigenesis appears to be celltype specific due to its diverse function in a given microenvironment [16]. In some types of cancer, high levels of SPARC expression have been shown to correlate with disease progression and poor prognosis. In melanoma cells, high levels of SPARC expression induce epithelial-mesenchymal transition and increases invasion and tumor progression $[17,18]$. High levels of SPARC are also associated with invasive meningioma [19] and osteosarcoma [20]. In glioma, SPARC promotes invasion, but delays tumor growth [21]. In other types of cancer, SPARC functions as a tumor suppressor. It inhibits the proliferation of breast cancer cells [22] and induces apoptosis in ovarian cancer cells [23]. In the majority of primary lung adenocarcinomas, SPARC silencing is associated with poor outcome [24]. In non-small cell lung cancer, SPARC expression is frequently down-regulated due to methylation of the tumor suppressor RASSF1A [25]. Similarly, in breast and prostate cancers and neuroblastoma, the majority of neoplastic cells do not express SPARC [12].

Previously, we synthesized peptides corresponding to the highly conserved structural domains of SPARC and tested their ability to inhibit angiogenesis [26]. To maintain the structural integrity of the native modules, cysteines within the peptides were linked with disulfide bonds during the synthesis. Minimal to no inhibitory activity was observed with the peptides corresponding to the Kazal module and the $\alpha$-helix of the EC domain. In contrast, the epidermal growth factor (EGF)-like module peptide FS-E strongly inhibited endothelial cell migration in vitro and angiogenesis in vivo. Reduction of the two disulfide bonds in the FS-E peptide completely abrogated the angiogenesis inhibitory effects, indicating that structural conformation is critical for this biological activity. We have now designed two additional SPARC peptides that structurally correspond to $\mathrm{N}$ - and C-terminal loops of the FS-E peptide: FSEN and FSEC, respectively. These peptides are smaller, less structurally complex, and easier to produce than the FS-E peptide. We show that both peptides block angiogenesis, although FSEC is more potent. We also demonstrate that FSEC effectively inhibits neuroblastoma tumor growth in a preclinical model.

\section{Results}

\section{Peptide design}

Our previous studies demonstrated that peptide FS-E, representing the $\mathrm{N}$-terminal EGF-like module of the SPARC follistatin domain, potently inhibits angiogenesis [26]. This module of SPARC is a $\beta$-hairpin, highly twisted by disulfide bonds that link cysteine 1 to cysteine 3 and cysteine 2 to cysteine 4 . The crystal structure of peptide FS-E shows that the two central cysteines are closely located (Figure 1). By linking cysteine 4 with cysteine 3 in lieu of cysteine 2 , separate $\mathrm{N}$ - and $\mathrm{C}$-terminal loops of the peptide can be produced without disturbing the native structure. Using this strategy, we synthesized the $\mathrm{N}$ - and C-terminal loops of peptide FS-E as two separate peptides, FSEN and FSEC, as detailed in Figure 1. Both peptides were folded into their native conformation by linking the cysteines that were placed at both ends. In the FSEN peptide, alanine was substituted for the unpaired cysteine. Corresponding scrambled control peptides, scFSEN and scFSEC that were designed to contain the same amino acids as peptides FSEN and FSEC in a random order, were synthesized without special modifications.

\section{Peptides FSEN and FSEC inhibit angiogenesis in vitro and in} vivo

Migration assays were performed with human umbilical vein endothelial cells (HUVEC) and each of the synthetic SPARC peptides to characterize their anti-angiogenic properties in vitro and to compare their potencies with the original peptide FS-E. As shown in Figure 2, the Cterminal loop peptide FSEC inhibited bFGF-stimulated endothelial cell migration with an $\mathrm{EC}_{50}$ of $\sim 1 \mathrm{pM}$, which was even lower than $\mathrm{EC}_{50}$ of $\sim 10 \mathrm{pM}$ of the original FS-E peptide. Higher concentrations of peptide FSEC did not inhibit endothelial cell migration, which is also a property of peptide FS-E [26] and the full-length SPARC [10]. Biphasic inhibition of endothelial cell migration is a characteristic feature of other natural inhibitors of angiogenesis, including thrombospondin-1 [27] and endostatin [28]. The N-terminal loop peptide, FSEN, showed weaker inhibition of bFGF-stimulated endothelial cell migration, with an $\mathrm{EC}_{50}$ of $\sim 2 \mathrm{nM}$. Neither peptide, tested at concentrations from $0.1 \mathrm{pM}$ to $100 \mu \mathrm{M}$, affected proliferation of HUVEC cells stimulated with bFGF (data not shown).

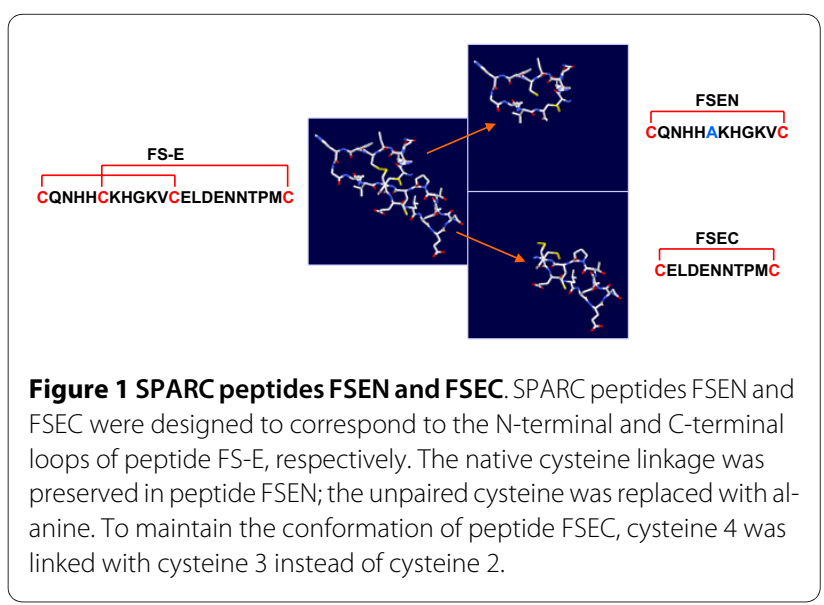


A

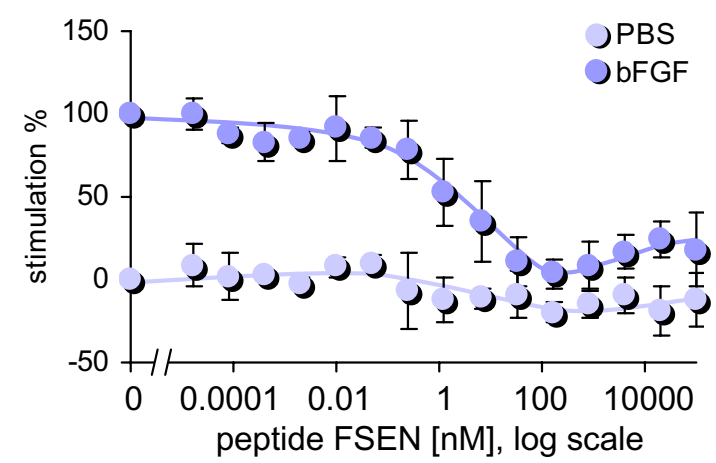

B

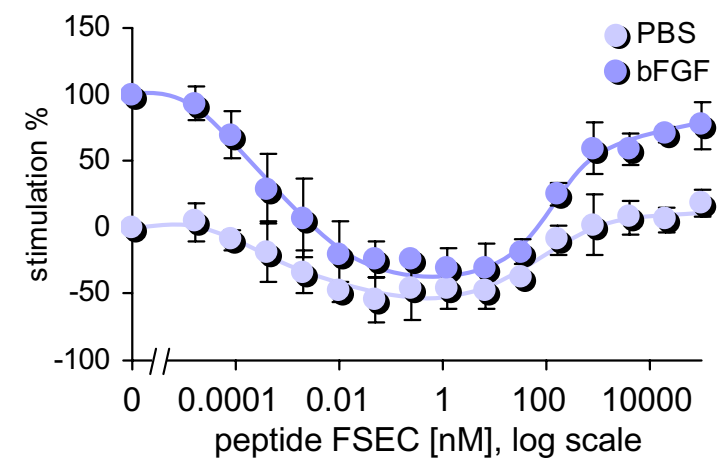

Figure 2 SPARC peptides FSEN and FSEC inhibit endothelial cell migration. HUVEC cells were treated with serial dilutions of SPARC peptides with or without $10 \mathrm{ng} / \mathrm{ml}$ bFGF in a modified Boyden chamber. Relative stimulation was calculated as percentage of bFGF-induced migration. (A) Peptide FSEN inhibited bFGF-stimulated endothelial migration with an $\mathrm{EC}_{50}$ of $\sim 2 \mathrm{nM}$. (B) Peptide FSEC displayed a strong dose-dependent inhibition of bFGFstimulated endothelial migration with an $\mathrm{EC}_{50} \sim 1 \mathrm{pM}$. Dark circles represent bFGF-stimulated migration; light circles represent basal migration in the absence of an activator.

The anti-angiogenic properties of the peptides were further characterized in vivo using the Matrigel plug assay. Matrigel plugs containing bFGF and either SPARC peptides FSEN or FSEC were less hemorrhagic than the positive control Matrigel plugs containing bFGF with or without scrambled SPARC peptides (Figure 3A). To quantify the anti-angiogenic effects of the peptides, we stained the endothelial cells in paraffin sections of the Matrigel plugs with green fluorescence using anti-CD31 antibody and visualized the perivascular pericytes with red fluorescence using anti- $\alpha$-smooth muscle actin (SMA) antibody (Figure 3B). The area occupied by each type of cells was quantified at low magnification in duplicate fields in each sample using ImagePro software. As shown in Figure 3C, the quantity of CD31-positive endothelial cells was statistically significantly decreased in the SPARC peptides-treated Matrigel plugs compared to the positive controls with bFGF alone $(\mathrm{p}<0.005)$. Although the area, occupied by SMA-positive pericytes in the Matrigel plugs containing the SPARC peptides was significantly smaller compared to the positive controls ( $\mathrm{p}$ $<0.005)$, there was no significant differences in the ratio of pericytes to endothelial cells ( $p>0.8$ ), indicating identical pericyte coverage. In the Matrigel plugs treated with

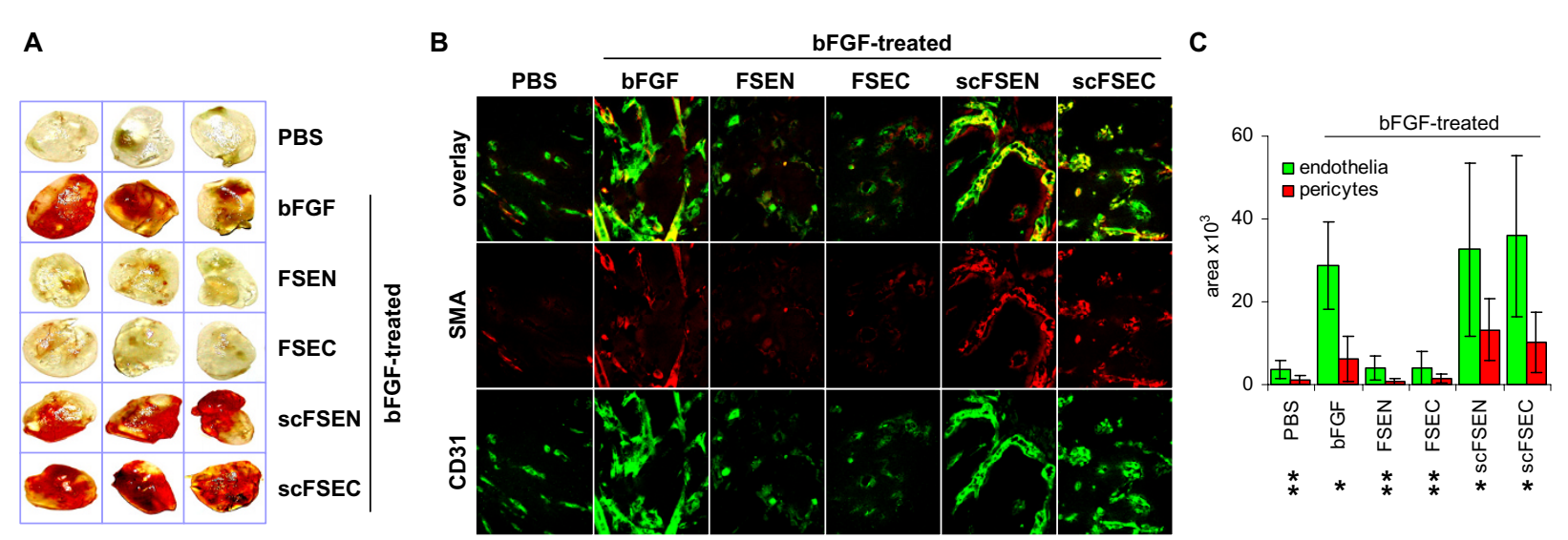

Figure 3 Inhibition of neovascularization by peptides FSEN and FSEC in the Matrigel plug assay. (A) Blood vessels developed for 7 days in nude mice, injected with Matrigel plugs containing $50 \mathrm{ng} / \mathrm{ml}$ bFGF alone (positive control), PBS (negative control), and bFGF with $10 \mu \mathrm{M}$ SPARC peptides FSEN, FSEC, or scrambled control peptides scFSEN and scFSEC. (B) For quantitative analysis of angiogenesis and blood vessel architecture, endothelial cells were visualized with green CD31 immunofluorescence, and pericytes were detected with red SMA antibody. Representative photographs at $\times 400$ magnification are shown. (C) The relative quantity of endothelial cells and pericytes was estimated by calculating the area occupied by green and red fluorescence (in pixels). There were statistically significant decreases in the blood vessel area and quantity of pericytes in the Matrigel plugs containing SPARC peptides compared to the positive control with bFGF alone (single asterisk) and from the negative control (double asterisk). 
scrambled peptides, no differences in endothelial cell ( $\mathrm{p}>$ $0.7)$ or pericyte area $(\mathrm{p}>0.3)$ were detected compared to the positive controls with bFGF alone.

\section{SPARC peptide FSEC potently inhibits neuroblastoma tumor growth}

To examine the anti-tumor activity of the SPARC peptides, mice with subcutaneous neuroblastoma xenografts were treated with either FSEN, FSEC, scrambled peptide scFSEN, or PBS 5 days/week for 2 weeks. Compared to control group, statistically significant inhibition of tumor growth was seen in the animals treated with the FSEC peptide, but not FSEN (Figure 4). In the FSEC-treated animals, the average tumor weight at the end of the experiment was $26 \%$ of the weight of the control tumors $(0.38 \pm 0.42 \mathrm{~g}$ vs $1.48 \pm 1.24 \mathrm{~g}$, respectively; $\mathrm{p}=0.01)$. In the group of animals treated with the peptide FSEN, the average weight of tumors was $88 \%$ of the controls, which was not statistically significant $(1.30 \pm 1.77 \mathrm{~g}, \mathrm{p}=0.83)$. The average weight of tumors resected from animals treated with the scrambled peptide was not different from the PBS controls $(1.51 \pm 1 \mathrm{~g}, \mathrm{p}=0.97)$.

Vascular architecture was initially evaluated on H\&E stained sections. In the control tumors, the blood vessels were structurally abnormal with dilated, tortuous appearance and prominent microvascular proliferation (MVP) (Figure $4 \mathrm{C}$ ). In xenografts treated with scrambled pep- tide, a similar architecture was noted with disorganized layers of endothelial and perivascular cells. Multiple areas of hemorrhage were present in the control and scrambled peptide-treated tumors. In the SPARC peptides-treated tumors, the blood vessel architecture was more normal, and there was no evidence of hemorrhage or MVP.

Immunofluorescent analysis of the tumors demonstrated a significant reduction in the quantity of endothelial cells in the SPARC peptide-treated xenografts compared to controls (Figure 5). The average area occupied by endothelial cells in FSEC-treated xenografts was $13 \pm 6 \%$ of the blood vessel area in the control xenografts $\left(5.9 \pm 2.6\right.$ pixels $\times 10^{3}$ vs $44.9 \pm 6.6$ pixels $\times 10^{3}$, respectively; $\mathrm{p}<0.001$ ). Peptide FSEN also inhibited angiogenesis in the xenografts, although less potently. The average area occupied by endothelial cells in the FSEN-treated tumors was $33 \pm 9 \%$ of the control $\left(15.0 \pm 4.0\right.$ pixels $\times 10^{3}$; $\mathrm{p}<0.001)$. In contrast, no significant difference in the quantity of endothelial cells in the xenografts treated with scrambled peptide or control vehicle was detected (42.4 \pm 13.1 pixels $\times 10^{3}, \mathrm{p}=0.67$ ).

The quantity of perivascular cells in each group corresponded to the level of angiogenesis. The average area occupied by pericytes in the tumors treated with peptides FSEC vs control tumors was $16 \pm 10 \%$ (6.2 \pm 4.0 pixels $\times 10^{3}$ vs $38.6 \pm 10.4$ pixels $\times 10^{3}$, respectively; $\mathrm{p}<0.001$ )

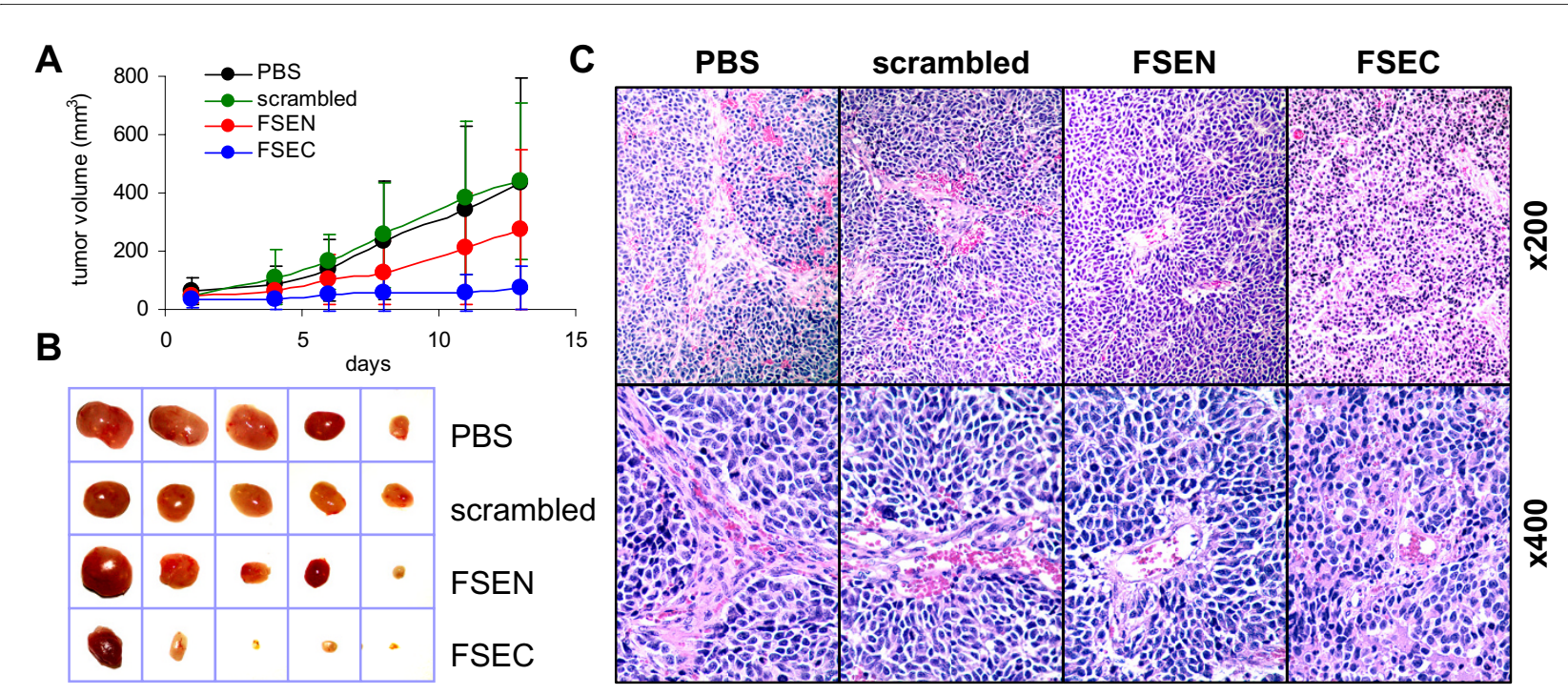

Figure 4 Inhibition of neuroblastoma tumor progression by SPARC peptides FSEN and FSEC in the preclinical model of neuroblastoma. (A) Mice with xenografted SMS-KCNR neuroblastoma cells received intraperitoneal injection of PBS, $10 \mathrm{mg} / \mathrm{kg}$ of the SPARC peptides FSEN or FSEC, or scrambled peptide sCFSEN five times a week for 2 weeks. Treatment with the SPARC peptide FSEC resulted in a statistically significant $(p<0.05)$ decrease in the average size of tumors starting from day 4 until the end of the treatment period. The average tumor weight was reduced to $26 \%$ ( $p=$ 0.01) of average control tumor weight. The average weight of tumors treated with peptide FSEN was reduced to $88 \%$, but the decrease was not statistically significant $(p=0.83)$. Scrambled peptide did not affect tumorigenicity of neuroblastoma xenografts $(102 \%, p=0.97)$. (B) Representative photographs of neuroblastoma tumors treated with the SPARC peptides. (C) Normalization of the blood vessels in the SPARC peptide-treated xenografts. H\&E staining of areas with large blood vessels at $\times 200$ and $\times 400$ magnification shows areas of extensive hemorrhage and MVP in control tumors and tumors treated with the scrambled peptides. In contrast, no evidence of hemorrhage or MVP was seen the SPARC peptide-treated tumors. 


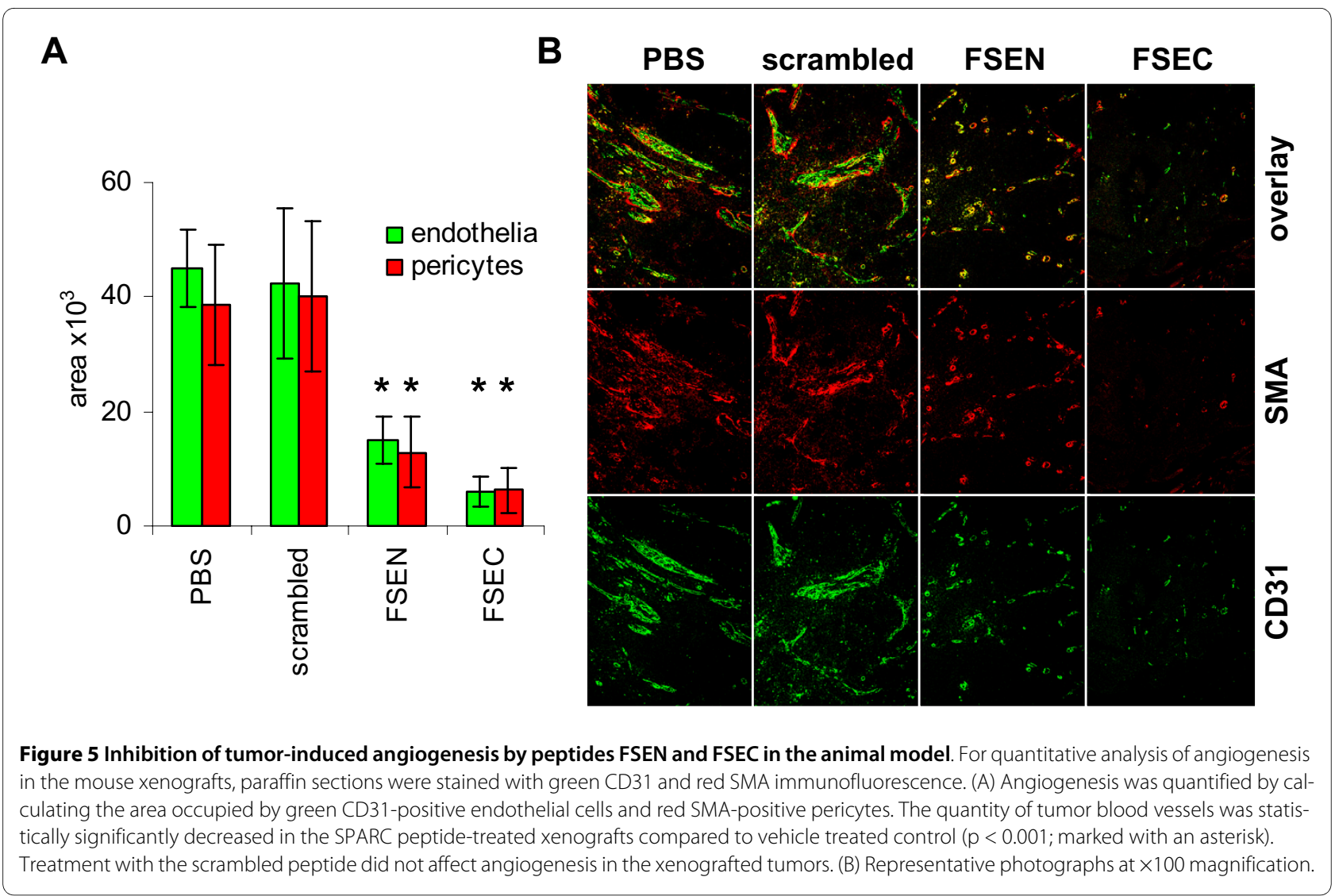

and $33 \pm 16 \%\left(12.8 \pm 6.2\right.$ pixels $\left.\times 10^{3} ; \mathrm{p}=0.004\right)$ for peptide FSEN (Figure 5). No difference in the quantity of pericytes in tumors treated with the scrambled peptide and controls was detected $\left(40.1 \pm 13.1\right.$ pixels $\times 10^{3}$; $\mathrm{p}=$ $0.84)$. Although pericyte-to-endothelial cell ratio was not affected by the treatment, differences in the blood vessel architecture were apparent between the control and SPARC peptide-treated tumors. In the xenografts treated with vehicle or scrambled peptide, the blood vessels exhibited abnormal architecture with multiple layers of hypertrophic endothelial cells which often lacked colocalized pericytes. In contrast, blood vessels in the SPARC peptides-treated tumors had more normal architecture, mainly consisting of a single layer of spindleshaped endothelial cells, enveloped by a layer of pericytes (Figure 6).

We used a novel approach to quantitatively assess blood vessel architecture by using 2-dimensional shape descriptors of Image J software that is similar to the method, previously described for 3-dimensional shapes [29]. Circularity is a measure of roundness of an object with value ranges from 0 to 1 , where 1 is a perfect circle. As shown in Figure 6B, the blood vessels in the peptidetreated tumors are more circular compared to the PBS and scrambled peptide-treated controls (Figure 6B). Aspect ratio reflects the shape of an object as the ratio of its height to its width. We found that the aspect ratio was significantly closer to 1 in the treated versus the control tumors, indicating that these vessels are less elongated. Solidity, which approximates density of an object, was appreciably higher in the peptides-treated xenografts, compared to tumors treated with PBS or scrambled peptide, indicating that the endothelial cells are spaced more compactly in the blood vessels in the SPARC peptidestreated tumors. We integrated all three shape descriptors into a coefficient of abnormality to quantitatively assess roundness, elongation, and the border shape of the blood vessels using a scale from 0 to 1 , with lower values reflective of more normal architecture. The scores for the blood vessels in the tumors treated with peptides FSEN and FSEC were significantly lower $(0.53 \pm 0.21$ and $0.56 \pm$ 0.20 , respectively) compared to the vessels in tumors, treated with PBS or scrambled peptide $(0.88 \pm 0.12$ and $0.93 \pm 0.05$, respectively).

\section{Discussion}

We have previously shown that full-length SPARC and SPARC peptide FS-E, that corresponds to the highly conserved EGF-like module of the follistatin domain, potently inhibit angiogenesis and neuroblastoma tumor growth in preclinical models $[10,26,30]$. The structure of the FS-E peptide is complex, and we have demonstrated 


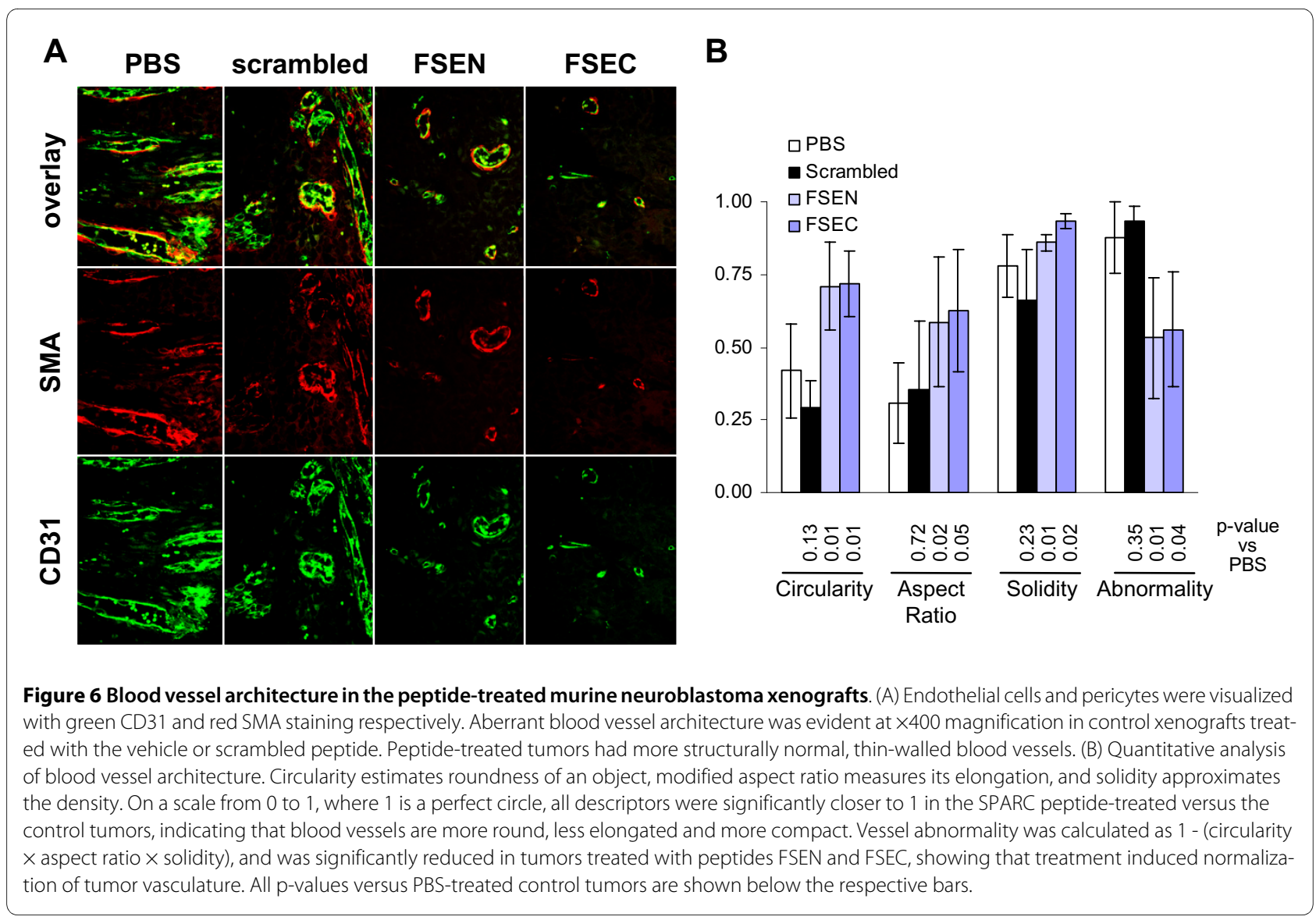

that its anti-angiogenic function is conformation-dependent [26]. In an effort to develop a therapeutic that may be suitable for clinical use, in this study we designed and synthesized two simply structured derivative peptides, FSEN and FSEC. Because proper structure is imperative to maintain activity of the FS-E peptide, peptides FSEN and FSEC were folded into their native conformation by linking the end cysteines during synthesis with disulfide bonds. This was possible due to the close proximity of the two central cysteines in the FS-E peptide [31]. Linking cysteine 4 with cysteine 3 instead of cysteine 2 allowed us to design peptides that correspond to amino acid sequences in the $\mathrm{N}$ - and $\mathrm{C}$-terminal loops without disturbing the native folding. We found that both FSEN and FSEC function as inhibitors of angiogenesis, although the FSEC peptide was more potent.

Due to potent anti-angiogenic activity in vitro, a dose of $10 \mathrm{mg} / \mathrm{kg}$ was administered 5 days a week to investigate the effects of SPARC peptides on tumor progression in the preclinical model. This is a lower amount than the 10 to $100 \mathrm{mg} / \mathrm{kg}$ daily doses that have been used to test other anti-angiogenic peptides in preclinical studies [28,32-35]. At this low dose, peptide FSEC significantly suppressed neuroblastoma tumor growth in experimental animals. Furthermore, consistent with properties of SPARC as an inhibitor of angiogenesis, the number of endothelial and perivascular cells was also significantly decreased in the peptide-treated animals, compared to controls.

Although the anti-tumor and anti-angiogenic effects of peptide FSEN were less potent, both SPARC peptides had profound effects on the architecture of tumor-induced blood vessels. In contrast to the structurally abnormal blood vessels that were seen in the control tumors, thin walled blood vessels were detected in the peptide-treated tumors, suggesting that treatment with FSEN and FSEC induced blood vessel normalization. Interestingly, hemorrhage was not detected in the peptide-treated tumors, whereas significant hemorrhage was detected in the control tumors.

Similar to the original SPARC peptide FS-E [26], the proper structural conformation may be essential to maintain the anti-angiogenic activity of the FSEC and FSEN peptides. Disulfide bonds are likely to be unstable in the reducing environment in vivo, leading to poor pharmacokinetic properties and decreased activity of the peptides. Stable analogs of disulfide bonds have been used to increase activity of other biologically active peptides [36], and we plan to use this approach to produce more stable analogs of peptides FSEC and FSEN. 
It is well established that cancer blood vessels are not structurally normal [37]. In tumors, multiple layers of hypertrophic endothelial cells alternate with areas in which endothelial cell coverage is lacking. Corresponding abnormalities in the deposition of the basement membrane are also commonly observed. Perivascular smooth muscle cells, which provide both mechanical and physiological support for the endothelial monolayer in normal blood vessels, fail to co-localize with endothelial cells in neoplastic blood vessels. These abnormalities disrupt the integrity of the blood vessels, resulting in a heterogeneous blood supply of the tumor tissue, vessel leakiness, and hemorrhage. Our recent evaluation of blood vessel architecture in a series of neuroblastoma tumors demonstrated that structurally abnormal blood vessels are commonly seen in high-risk tumors, and the presence of MVP was statistically significantly associated with decreased survival [38].

Normalization of neoplastic blood vessels has been demonstrated with other anti-angiogenic therapeutics [37], and recently the extent of vascular normalization following treatment with an anti-VEGF therapy was shown to be predictive of outcome in patients with glioblastoma [39]. Emerging evidence also indicates that by normalizing the abnormal structure and function of tumor vasculature, anti-angiogenic agents can alleviate hypoxia and increase the efficacy of conventional therapies [37]. A recently completed phase I dose-escalation study of an anti-VEGF agent has provided evidence of both vascular normalization and sensitization of rectal tumors to radiation $[40,41]$. Using a simple method to quantitatively assess blood vessel architecture, we show that treatment with either FSEC or FSEN similarly normalizes the tumor vasculature. Normalization of blood vessels may enhance drug delivery to the tumor tissue and improve efficacy of chemotherapeutic agents. A better understanding of the molecular and cellular basis of vascular normalization may ultimately lead to more effective strategies for combining chemotherapy and radiation with agents that are capable of inducing blood vessel normalization.

\section{Conclusion}

In summary, we have designed and synthesized SPARCderived peptides FSEN and FSEC that are easy to produce and demonstrated that they function as inhibitors of angiogenesis in vitro and in vivo. The potent anti-tumor activity of SPARC peptide FSEC in a preclinical model of neuroblastoma indicates that it may be an effective treatment for children with high-risk neuroblastoma, as well as other malignancies. Similar to other anti-angiogenic agents, the SPARC peptides induced normalization of blood vessels and thus may enhance drug delivery to the tumor tissue. Preclinical studies testing the activity of peptide FSEC in combination with chemotherapy are planned.

\section{Materials and methods \\ Peptide synthesis}

SPARC peptides FSEN (CQNHHAKHGKVC) and FSEC (CELDENNTPMC) were synthesized at Alpha Diagnostics International (San Antonio, TX) using fmoc/tboc chemistry as cyclic cysteine-linked molecules, with disulfide bonds unambiguously formed during peptide synthesis. The purity of the peptides was assessed by highperformance liquid chromatography, and the molecular mass was checked by mass spectrometry. Control scrambled peptides scFSEN (KCGHKHQCAVHN) and scFSEC (MEPECNLNCTD), which contain the same amino acids as peptides FSEN and FSEC in a random order, were made without special modifications.

\section{Cell lines}

HUVEC cells (VEC Technologies, Rensselaer, NY) were maintained at $5 \% \mathrm{CO}_{2}$ in EGM media (Lonza, Walkersville, MD) supplemented with 5\% FBS (Life Technologies, Carlsbad, CA). Neuroblastoma cell line SMS-KCNR was grown at 5\% $\mathrm{CO}_{2}$ in RPMI 1640 (Life Technologies) supplemented with $10 \%$ heat-inactivated FBS and $1 \%$ penicillin/streptomycin.

\section{Endothelial cell migration assay}

To characterize the anti-angiogenic properties of the peptides in vitro, migration assays were performed in a modified Boyden chamber with HUVEC cells in EBM media (Lonza) containing $0.01 \%$ BSA as described [42]. Serial dilutions of each of the synthetic SPARC peptides, starting at $100 \mu \mathrm{M}$ were assayed with or without $10 \mathrm{ng} / \mathrm{ml}$ bFGF (National Cancer Institute Preclinical Repository, Frederick, MD). At least three independent experiments were performed for each peptide. To compare multiple experiments, the data were represented as the percentage of bFGF-induced stimulation using the difference between bFGF-induced migration and background migration in EBM alone as $100 \%$ control.

\section{Endothelial cell proliferation assay}

The effect of SPARC peptides on endothelial cell proliferation was measured in 96-well plates with HUVEC cells in EBM media supplemented with $0.5 \%$ FBS. Serial $\times 10$ dilutions of SPARC peptides from $0.1 \mathrm{pM}$ to $100 \mu \mathrm{M}$ with and without $10 \mathrm{ng} / \mathrm{ml}$ bFGF were added to quadruplicate wells, cells were grown at $37^{\circ} \mathrm{C}$ in $5 \% \mathrm{CO}_{2}$ for 24 and $48 \mathrm{~h}$, and proliferation was determined with the CellTiter cell proliferation assay (Promega, Madison, WI). 


\section{Matrigel assay}

To characterize the anti-angiogenic properties of the peptides in vivo, Matrigel assays were performed in 4- to 6week-old homozygous athymic nude mice (Harlan, Madison, WI). SPARC peptides FSEN, FSEC and corresponding scrambled peptides scFSEN and scFSEC were added to $0.4 \mathrm{ml}$ of Growth Factor-reduced Matrigel (BD Biosciences, Bedford, MA) containing 10 units $/ \mathrm{ml}$ heparin and $50 \mathrm{ng} / \mathrm{ml}$ bFGF to a final concentration of $10 \mu \mathrm{M}$. At least 5 animals were subcutaneously injected with Matrigel plugs containing bFGF and each SPARC peptide. Matrigel plugs with bFGF and no peptides served as positive controls. Matrigels without either bFGF or peptides were used as negative controls. Mice were sacrificed 7 days after the Matrigel injections, gels were recovered by dissection, photographed, fixed in formaldehyde, and embedded in paraffin.

\section{Xenograft model}

A neuroblastoma xenograft model was used to examine the anti-tumor activity of peptides FSEN and FSEC. Briefly, 4-6 week old athymic nude mice were injected subcutaneously with $0.2 \mathrm{ml}$ PBS containing $1 \times 10^{7} \mathrm{SMS}$ KCNR neuroblastoma cells. Once tumors were palpable $\left(\sim 70 \mathrm{~mm}^{3}\right)$, animals were randomized into four treatment groups with at least 6 animals per group. Experimental animals received intraperitoneal injection of $10 \mathrm{mg} / \mathrm{kg}$ of the SPARC peptides FSEN or FSEC, or scrambled peptide scFSEN ( $0.3 \mathrm{mg}$ of the peptide in $150 \mu \mathrm{l}$ of PBS) 5 days a week for 2 weeks. Animals in the control group were injected with PBS without the peptide. Possible toxic effects of the treatment were assessed by monitoring the animals for signs of distress such as difficulty in ambulating, ulceration, cachexia, respiratory distress, loss of 15$20 \%$ body weight, or gain of $10 \%$ body weight. The size of the tumors was determined every 2-3 days by external measurements with a caliper. At the end of treatment, animals were euthanized using $\mathrm{CO}_{2}$ followed by cervical dislocation. Tumors were removed, measured, weighed, and photographed. Tissue was fixed with $10 \%$ buffered formalin, embedded in paraffin and $4 \mu \mathrm{m}$-thick sections were prepared for histologic evaluation. All animal studies were approved by the IACUC at the University of Chicago.

\section{Histological analysis and immunofluorescence}

Four- $\mu$ m-thick sections were stained with H\&E for histological evaluation. The entire tissue section was evaluated for vascular morphology. Vessels with thickened walls containing complete layers of hypertrophied endothelial cells plus additional layers of vascular mural cells were classified as positive for MVP as previously described [38]. Vessels with normal vessel architecture and no more than a single layer of flat, spindle shaped endothelial cells were characterized as MVP negative. For quantitative analysis of angiogenesis, 4- $\mu$ m-thick sections were stained with anti-CD31 antibody (Santa Cruz Biotechnology Inc., Santa Cruz, CA) at a 1:50 dilution followed by FITC-labeled secondary antibody. To characterize the blood vessel architecture, pericytes were visualized with red fluorescence using anti- $\alpha$-SMA antibody (SigmaAldrich, St. Louis, MO) at 1:100 dilution. The area occupied by each cell type was quantified at $\times 100$ magnification in duplicate fields in each sample using ImagePro software. Two-dimensional shape descriptors of Image J software were used to quantitatively assess blood vessel architecture. Circularity was calculated as $4 \pi \times$ area/ perimeter $^{2}$, modified aspect ratio was measured as object's width/length, and solidity was calculated as a ratio of an object area/convex hull (outermost outline). Coefficient of abnormality was calculated as 1 - (circularity $\times$ aspect ratio $\times$ solidity).

\section{Statistical analysis}

All in vitro experiments were repeated at least in triplicates and standard deviations were calculated. All animal studies had at least 5 mice per group and mean values of the tumor volumes, weights, and vessel densities were compared. All the quantitative values obtained in the experiments were evaluated using paired Student's t-test. A p-value of 0.05 was required to ascertain statistical significance.

\section{Competing interests}

A provisional patent application has been filed for the SPARC peptides FSEN and FSEC. The authors declare no additional conflicting interests in relation to the described work.

\section{Authors' contributions}

SC conceived and supervised the study, AC and LJG designed the peptides, performed in vitro experiments, imaging studies and data analysis, RP performed pathological analysis, JAS, PL and HRS assisted with in vitro studies, QY and $Y T$ did the xenograft studies. All authors participated in preparation of the manuscript.

\section{Acknowledgements}

This work was supported by NIH RO1 Grant CA106276 (SLC), The Super Jake Foundation (SLC), Little Heroes Cancer Research Foundation (SLC), the Neuroblastoma Children's Cancer Society (SLC), the Elise Anderson Neuroblastoma Research Fund (SLC), Fighting Children's Cancer Foundation (AC), and Children's Neuroblastoma Cancer Foundation (AC).

\section{Author Details}

1Department of Pediatrics, University of Chicago, 900 East 57th Street, KCBD Rm. 5240, Chicago, IL 60637, USA, 2Department of Pediatrics, Stroger Hospital, 1900 W Polk, Suite 1100, Chicago, IL 60612, USA and ${ }^{3}$ Department of

Pediatrics, University of Chicago, 900 East 57th Street, KCBD Rm. 5100, Chicago, IL 60637, USA

Received: 16 December 2009 Accepted: 4 June 2010

Published: 4 June 2010

\section{References}

1. Maris JM, Hogarty MD, Bagatell R, Cohn SL: Neuroblastoma. Lancet 2007, 369:2106-2120. 
2. Oppedal BR, Oien O, Jahnsen T, Brandtzaeg P: N-myc amplification in neuroblastomas: histopathological, DNA ploidy, and clinical variables. J Clin Pathol 1989, 42:1 148-1152.

3. Meitar D, Crawford SE, Rademaker AW, Cohn SL: Tumor angiogenesis correlates with metastatic disease, $\mathrm{N}$-myc amplification, and poor outcome in human neuroblastoma. J Clin Oncol 1996, 14:405-414.

4. Eggert A, Ikegaki N, Kwiatkowski J, Zhao H, Brodeur GM, Himelstein BP High-level expression of angiogenic factors is associated with advanced tumor stage in human neuroblastomas. Clin Cancer Res 2000, 6:1900-8.

5. Katzenstein HM, Rademaker AW, Senger C, Salwen HR, Nguyen NN, Thorner PS, Litsas L, Cohn SL: Effectiveness of the angiogenesis inhibitor TNP-470 in reducing the growth of human neuroblastoma in nude mice inversely correlates with tumor burden. Clin Cancer Res 1999, 5:4273-4278.

6. Chesler L, Goldenberg DD, Seales IT, Satchi-Fainaro R, Grimmer M, Collins R, Struett C, Nguyen KN, Kim G, Tihan T, et al: Malignant progression and blockade of angiogenesis in a murine transgenic model of neuroblastoma. Cancer Res 2007, 67:9435-9442.

7. Shimada H, Ambros IM, Dehner LP, Hata J, Joshi WV, Roald B, Stram DO, Gerbing RB, Lukens JN, Matthay KK, et al:: The International Neuroblastoma Pathology Classification (the Shimada System). Cancer 1999, 86:364-372.

8. Ambros IM, Attarbaschi A, Rumpler S, Luegmayr A, Turkof E, Gadner H, Ambros PF: Neuroblastoma cells provoke Schwann cell proliferation in vitro. Med Pediatr Oncol 2001, 36:163-8.

9. Kwiatkowski JL, Rutkowski JL, Yamashiro DJ, Tennekoon GI, Brodeur GM: Schwann cell-conditioned medium promotes neuroblastoma survival and differentiation. Cancer Res 1998, 58:4602-6.

10. Chlenski A, Liu S, Crawford SE, Volpert OV, DeVries GH, Evangelista A, Yang Q, Salwen HR, Farrer R, Bray J, et al: SPARC is a key Schwannian-derived inhibitor controlling neuroblastoma tumor angiogenesis. Cancer Res 2002, 62:7357-63.

11. Sage $H$, Johnson C, Bornstein P: Characterization of a novel serum albumin-binding glycoprotein secreted by endothelial cells in culture. J Biol Chem 1984, 259:3993-4007.

12. Tai IT, Tang MJ: SPARC in cancer biology: its role in cancer progression and potential for therapy. Drug Resist Updat 2008, 11:231-246.

13. Mundlos S, Schwahn B, Reichert T, Zabel B: Distribution of osteonectin mRNA and protein during human embryonic and fetal development. $J$ Histochem Cytochem 1992, 40:283-291.

14. Hasselaar P, Sage EH: SPARC antagonizes the effect of basic fibroblast growth factor on the migration of bovine aortic endothelial cells. J Cell Biochem 1992, 49:272-83.

15. Yunker CK, Golembieski W, Lemke N, Schultz CR, Cazacu S, Brodie C, Rempel SA: SPARC-induced increase in glioma matrix and decrease in vascularity are associated with reduced VEGF expression and secretion. Int J Cancer 2008, 122:2735-2743.

16. Chlenski A, Cohn SL: Modulation of matrix remodeling by SPARC in neoplastic progression. Semin Cell Dev Biol 2010, 21:55-65.

17. Ledda MF, Adris S, Bravo Al, Kairiyama C, Bover L, Chernajovsky Y, Mordoh J, Podhajcer OL: Suppression of SPARC expression by antisense RNA abrogates the tumorigenicity of human melanoma cells. Nat Med 1997, 3:171-176.

18. Robert G, Gaggioli C, Bailet O, Chavey C, Abbe P, Aberdam E, Sabatie E, Cano A, Garcia dH, Ballotti R, et al:: SPARC represses E-cadherin and induces mesenchymal transition during melanoma development. Cancer Res 2006, 66:7516-7523.

19. Rempel SA, Ge S, Gutierrez JA: SPARC: a potential diagnostic marker of invasive meningiomas. Clin Cancer Res 1999, 5:237-241.

20. Dalla-Torre CA, Yoshimoto M, Lee CH, Joshua AM, de Toledo SR, Petrilli AS, Andrade JA, Chilton-MacNeill S, Zielenska M, Squire JA: Effects of THBS3, SPARC and SPP1 expression on biological behavior and survival in patients with osteosarcoma. BMC Cancer 2006, 6:237.

21. Schultz C, Lemke N, Ge S, Golembieski WA, Rempel SA: Secreted protein acidic and rich in cysteine promotes glioma invasion and delays tumor growth in vivo. Cancer Res 2002, 62:6270-6277.

22. Dhanesuan N, Sharp JA, Blick T, Price JT, Thompson EW: Doxycyclineinducible expression of SPARC/Osteonectin/BM40 in MDA-MB-231 human breast cancer cells results in growth inhibition. Breast Cancer Res Treat 2002, 75:73-85.
23. Yiu GK, Chan WY, Ng SW, Chan PS, Cheung KK, Berkowitz RS, Mok SC: SPARC (secreted protein acidic and rich in cysteine) induces apoptosis in ovarian cancer cells. Am J Pathol 2001, 159:609-22.

24. Suzuki M, Hao C, Takahashi T, Shigematsu H, Shivapurkar N, Sathyanarayana UG, lizasa T, Fujisawa T, Hiroshima K, Gazdar AF: Aberrant methylation of SPARC in human lung cancers. Br J Cancer 2005, 92:942-948

25. Agathanggelou A, Bieche I, Ahmed-Choudhury J, Nicke B, Dammann R, Baksh S, Gao B, Minna JD, Downward J, Maher ER, et al.: Identification of novel gene expression targets for the Ras association domain family 1 (RASSF1A) tumor suppressor gene in non-small cell lung cancer and neuroblastoma. Cancer Res 2003, 63:5344-5351.

26. Chlenski A, Liu S, Baker LJ, Yang Q, Tian Y, Salwen HR, Cohn SL: Neuroblastoma angiogenesis is inhibited with a folded synthetic molecule corresponding to the epidermal growth factor-like module of the follistatin domain of SPARC. Cancer Res 2004, 64:7420-7425.

27. Dawson DW, Bouck NP: Thrombospondin as an Inhibitor of Angiogenesis. In Antiangiogenic Agents in Cancer Therapy Edited by: Teicher BA. Totowa, NJ: Humana Press Inc; 1999:185-203.

28. Celik I, Surucu O, Dietz C, Heymach JV, Force J, Hoschele I, Becker CM, Folkman J, Kisker O: Therapeutic efficacy of endostatin exhibits a biphasic dose-response curve. Cancer Res 2005, 65:11044-11050.

29. Stockmann C, Doedens A, Weidemann A, Zhang N, Takeda N, Greenberg $\mathrm{Jl}$, Cheresh DA, Johnson RS: Deletion of vascular endothelial growth factor in myeloid cells accelerates tumorigenesis. Nature 2008, 456:814-818.

30. Chlenski A, Liu S, Guerrero L, Yang Q, Tian Y, Salwen HR, Zage P, Cohn SL: SPARC expression is associated with impaired tumor growth, inhibited angiogenesis and changes in the extracellular matrix. Int J Cancer 2006, 118:310-316.

31. Hohenester E, Maurer P, Timpl R: Crystal structure of a pair of follistatinlike and EF-hand calcium- binding domains in BM-40. Embo J 1997, 16:3778-86

32. Reiher FK, Volpert OV, Jimenez B, Crawford SE, Dinney CP, Henkin J, Haviv F, Bouck NP, Campbell SC: Inhibition of tumor growth by systemic treatment with thrombospondin-1 peptide mimetics. Int J Cancer 2002, 98:682-9.

33. Haviv F, Bradley MF, Kalvin DM, Schneider AJ, Davidson DJ, Majest SM, McKay LM, Haskell CJ, Bell RL, Nguyen B, et al:: Thrombospondin-1 mimetic peptide inhibitors of angiogenesis and tumor growth: design, synthesis, and optimization of pharmacokinetics and biological activities. J Med Chem 2005, 48:2838-2846.

34. Maeshima Y, Colorado PC, Torre A, Holthaus KA, Grunkemeyer JA, Ericksen MB, Hopfer H, Xiao Y, Stillman IE, Kalluri R: Distinct antitumor properties of a type IV collagen domain derived from basement membrane. $J$ Biol Chem 2000, 275:21340-21348.

35. Mirochnik Y, Aurora A, Schulze-Hoepfner FT, Deabes A, Shifrin V, Beckmann R, Polsky C, Volpert OV: Short pigment epithelial-derived factor-derived peptide inhibits angiogenesis and tumor growth. Clin Cancer Res 2009, 15:1655-1663.

36. Nguyen T, Pickett CB: Regulation of rat glutathione S-transferase Ya subunit gene expression. DNA-protein interaction at the antioxidant responsive element. J Biol Chem 1992, 267:13535-9.

37. Jain RK: Normalization of tumor vasculature: an emerging concept in antiangiogenic therapy. Science 2005, 307:58-62.

38. Peddinti R, Zeine R, Luca D, Seshadri R, Chlenski A, Cole K, Pawel B, Salwen $H R$, Maris JM, Cohn SL: Prominent microvascular proliferation in clinically aggressive neuroblastoma. Clin Cancer Res 2007, 13:3499-3506.

39. Sorensen AG, Batchelor TT, Zhang WT, Chen PJ, Yeo P, Wang M, Jennings D. Wen PY, Lahdenranta J, Ancukiewicz M, et al:: A "vascular normalization index" as potential mechanistic biomarker to predict survival after a single dose of cediranib in recurrent glioblastoma patients. Cancer Res 2009, 69:5296-5300

40. Willett CG, Boucher Y, Duda DG, di TE, Munn LL, Tong RT, Kozin SV, Petit L, Jain RK, Chung DC, et al: Surrogate markers for antiangiogenic therapy and dose-limiting toxicities for bevacizumab with radiation and chemotherapy: continued experience of a phase I trial in rectal cancer patients. J Clin Oncol 2005, 23:8136-8139.

41. Jain RK, Duda DG, Clark JW, Loeffler JS: Lessons from phase III clinical trials on anti-VEGF therapy for cancer. Nat Clin Pract Oncol 2006, 3:24-40. 
42. Huang D, Rutkowski JL, Brodeur GM, Chou PM, Kwiatkowski JL, Babbo A, Cohn SL: Schwann cell-conditioned medium inhibits angiogenesis. Cancer Res 2000, 60:5966-71.

doi: $10.1186 / 1476-4598-9-138$

Cite this article as: Chlenski et al., Anti-angiogenic SPARC peptides inhibit progression of neuroblastoma tumors Molecular Cancer 2010, 9:138

Submit your next manuscript to BioMed Central and take full advantage of:

- Convenient online submission

- Thorough peer review

- No space constraints or color figure charges

- Immediate publication on acceptance

- Inclusion in PubMed, CAS, Scopus and Google Scholar

- Research which is freely available for redistribution

Submit your manuscript at www.biomedcentral.com/submit 